ORIGINAL RESEARCH

\title{
Vasopressin for Septic Shock in a Medical-Surgical Intensive Care Unit
}

\author{
Arpita Patel, Arielle Beauchesne, Nina Bredenkamp, Rumi McGloin, Sarah N Stabler, \\ and Krystin Boyce
}

\begin{abstract}
Background: Critically ill patients often need vasopressors to treat hypotension related to septic shock and to maintain adequate systemic perfusion. Although the 2017 guidelines of the Surviving Sepsis Campaign recommend norepinephrine as first-line therapy, they also state that vasopressin may be considered as an adjunctive agent for patients with refractory shock. Limited evidence is available for directing optimal administration of vasopressin. As such, prescribing practices are not standardized and may vary according to the particular clinician, the clinical scenario, and various patient-specific factors.
\end{abstract}

Objectives: To review the current practice of administering concomitant norepinephrine and vasopressin therapy to patients with septic shock, to describe variability in vasopressin administration, and to evaluate effects on patient safety in a medical-surgical intensive care unit (ICU).

Methods: This single-centre retrospective chart review involved 100 adult patients admitted to the ICU who received vasopressin and norepinephrine for septic shock between April and December 2017. The data were analyzed with descriptive statistics.

Results: The mean time to initiation of vasopressin was 12.0 (standard deviation [SD] 21.6) $\mathrm{h}$ after initiation of norepinephrine. The mean dose of norepinephrine at the time of vasopressin initiation was 29.5 (SD 19.7) $\mu \mathrm{g} / \mathrm{min}$. The mean vasopressin dose prescribed was 0.04 (SD 0.03) units/min, with a range of tapering and discontinuation regimens. The mean duration of vasopressin therapy was 49.1 (SD 65.2) h, and vasopressin was discontinued before norepinephrine in 49 of the patients. A total of 60 hypotensive events occurred after vasopressor discontinuation and were more common when vasopressin was discontinued before norepinephrine.

Conclusions: Vasopressin dosing was comparable to that reported elsewhere; however, discontinuation practices were inconsistent. These results show that variability in the literature supporting vasopressin use has led to variability in vasopressin administration and discontinuation practices; however, correlation with improvement in clinical outcomes, such as mortality or ICU length of stay, is unclear, and further research is required to determine the ideal approach to vasopressin use.

\section{RÉSUMÉ}

Contexte : Les patients gravement malades nécessitent souvent un vasopresseur pour traiter l'hypotension liée au choc septique et pour préserver une perfusion systémique adéquate. Bien que les directives de 2017 de la campagne Surviving Sepsis recommandent la norépinephrine en guise de thérapie de première ligne, elles précisent également que la vasopressine pourrait être envisagée comme agent d'appoint pour les patients présentant des chocs réfractaires. Seules des données probantes limitées soutiennent l'administration optimale de la vasopressine. Les pratiques de prescription proprement dites ne sont pas standardisées et peuvent varier selon le clinicien, le scénario clinique et les divers facteurs particuliers au patient.

Objectifs : Examiner la pratique actuelle d'administration de la norépinephrine concomitante à la thérapie de vasopressine aux patients ayant subi un choc septique, décrire la variabilité d'administration de la vasopressine et évaluer les effets sur la sécurité du patient dans une unité de soins intensifs (USI) médicale-chirurgicale.

Méthodes : Cet examen rétrospectif unicentrique des dossiers portait sur 100 patients adultes admis dans une USI, ayant reçu de la vasopressine et de la norépinephrine en réponse à des chocs septiques entre avril et décembre 2017. Les données ont été analysées à l'aide de statistiques descriptives.

Résultats : Le temps moyen du début de l'administration de la vasopressine était de $12 \mathrm{~h}$ (écart type [É.T.] 21,6) après le début de l'administration de la norépinephrine. La dose moyenne de norépinephrine au moment du début de l'administration de la vasopressine était de 29,5 (É.T. 19,7) $\mu \mathrm{g} / \mathrm{min}$. La dose moyenne de vasopressine prescrite était de 0,04 (É.T. 0,03) unités/min, avec une gamme de posologies dégressives et d'abandons. La durée moyenne de la thérapie à la vasopressine était de 49,1 h (É.T. 65,2), et 49 patients ont abandonné la vasopressine avant l'abandon de la norépinephrine. Un total de 60 événements hypotenseurs se sont produits après l'abandon du vasopresseur et ils étaient plus fréquents lors de l'abandon de la vasopressine précédant celui de la norépinephrine.

Conclusions : Le dosage de vasopressine était comparable à celui indiqué dans d'autres études; cependant, les pratiques d'abandon étaient 
Keywords: norepinephrine, vasopressin, intensive care unit, septic shock

\section{Can J Hosp Pharm. 2020;73(3):209-15}

\section{INTRODUCTION}

Cepsis and septic shock are associated with circulatory failure in $\checkmark$ response to an infective and inflammatory process, leading to high in-hospital mortality rates, including in the intensive care unit (ICU). Sepsis is defined as life-threatening organ dysfunction caused by an unregulated host response to infection. ${ }^{1}$ Patients with sepsis may experience distributive shock (of which septic shock is the most common form), a condition in which tissue perfusion decreases through a variety of vasodilatory mechanisms, metabolic and cellular abnormalities, and a prothrombotic state leading to microvascular thrombosis. ${ }^{1,2}$ In the ICU, septic shock is the most common cause of death and is associated with complications such as irreversible organ dysfunction and prolongation of ICU and hospital length of stay. ${ }^{2-5}$ The 2017 guidelines of the Surviving Sepsis Campaign (SSC) for management of septic shock provide evidence-based recommendations on immediate fluid resuscitation, administration of broad-spectrum antibiotics, and initial vasopressor therapy. ${ }^{6}$

Refractory hypotension is treated with vasopressors to increase systemic vascular resistance and therefore perfusion, which increases oxygen delivery to essential organ tissue, thereby minimizing cellular injury and death. ${ }^{1}$ According to the SSC guidelines, norepinephrine is the first-line vasopressor used to maintain target mean arterial pressure in patients with septic shock (strong recommendation, moderate quality of evidence). ${ }^{6}$ This drug exhibits its vasoconstrictive effects through agonism, primarily on $\alpha$-adrenergic receptors, with lesser effects on $\beta$ adrenergic receptors, thus leading to an increase in global systemic vascular resistance. ${ }^{3}$ In recent years, small trials and a systematic review and meta-analysis have suggested that the adjunctive use of catecholamine-sparing agents such as vasopressin may improve survival in this clinical context. ${ }^{4,7}$ Concomitant infusion of vasopressin may be used in cases of refractory septic shock to reach or maintain target mean arterial pressure and/or to decrease catecholamine requirements, which may prove particularly beneficial for patients with malignant arrhythmias or increased myocardial demand associated with high catecholamine load., Conversely, each additional medication increases the potential for complications and adverse effects. As such, the addition of incohérentes. Ces résultats démontrent que l'indétermination de l'information publiée dans la littérature soutenant l'utilisation de la vasopressine a entraîné une fluctuation dans l'administration de la vasopressine et des pratiques d'abandon; cependant, la corrélation entre l'usage de la vasopressine et l'amélioration des résultats cliniques, comme la mortalité ou la durée du séjour en USI, n'est pas claire, et davantage de recherches sont nécessaires pour déterminer l'approche idéale à adopter à l'égard de l'utilisation de la vasopressine.

Mots-clés : norépinephrine, vasopressine, unité de soins intensifs, choc septique adjunctive agents is based on the clinician's judgment, taking into account various patient-specific factors.

Arginine vasopressin is a non-adrenergic vasoconstrictor that restores serum osmolality, blood volume, and pressure by directly constricting vascular smooth muscle., ${ }^{3,5}$ Vasopressin increases intracellular calcium by direct action on $G$ protein-coupled vascular (V1) receptors, causing vasoconstriction; it also inhibits the cytokine interleukin-1, decreasing vascular endothelial production of nitric oxide and thereby reducing nitric oxidemediated vasodilation. ${ }^{3,5}$ These vasoconstrictive effects are less pronounced in the cerebral, coronary, and renal vasculature, which makes vasopressin an appealing alternative for patients in whom these effects may be particularly deleterious. ${ }^{3,5}$ Furthermore, it has been proposed that septic shock induces a vasopressin-deficient state ${ }^{8-14}$; a vasopressin infusion may thus replenish the depleted endogenous supply, in addition to providing essential hemodynamic support. Unlike norepinephrine, vasopressin has no effect on the $\beta$-adrenergic receptor; hence, it may be an attractive therapeutic alternative for maintaining hemodynamic stability in patients exhibiting dysrhythmias, particularly those requiring high doses of catecholamines. ${ }^{3,5,15}$

There is limited evidence about the optimal dose and titration of vasopressin. Although there has been substantial heterogeneity in the dose of vasopressin administered in various studies (ranging from 0.01 to 0.1 units $/ \mathrm{min}$ ), low doses of this drug have consistently been associated with a reduction in norepinephrine requirements to maintain target blood pressure, with inconsistent effects on clinically relevant outcomes. ${ }^{4,6-10,13}$ Higher doses have not shown additional clinical benefits in terms of survival or the number of kidney failure-free days. ${ }^{8}$ One meta-analysis reported a small mortality benefit when patients received vasopressin as an adjunct to norepinephrine. ${ }^{13}$ The VASST trial (Vasopressin versus Norepinephrine Infusion in Patients with Septic Shock) compared the adjunctive use of vasopressin and norepinephrine with norepinephrine alone in patients with initiation of vasopressors for septic shock. ${ }^{4}$ Although the patients did not exhibit vasopressor-refractory shock (mean arterial pressure $72 \mathrm{~mm} \mathrm{Hg}$ at the time of randomization), the study found no difference in overall mortality, length of stay, or 
adverse effects; however, a subgroup analysis suggested a reduction in 28-day mortality when vasopressin was used in patients who required lower doses of norepinephrine $(5-14 \mu \mathrm{g} / \mathrm{min}) .{ }^{4}$ Other researchers have hypothesized that early addition of vasopressin, in conjunction with steroids, may reduce the progression of organ failure and shorten the duration of shock, but their study results have been inconclusive. ${ }^{4,8,16-18}$ Previous studies have shown that discontinuation of vasopressin before norepinephrine may lead to more episodes of "clinically significant hypotension", but does not correlate with a difference in clinically relevant secondary outcomes such as mortality or ICU length of stay. ${ }^{10,14}$

Optimal dosing, titration, indications, and duration of vasopressin therapy remain controversial. Despite conflicting and limited evidence regarding positive effects on outcomes, particularly in patients with refractory septic shock, our institution continues to routinely use vasopressin $(0.04 \mathrm{units} / \mathrm{min})$ as adjunctive therapy to norepinephrine, with variation among clinicians with regard to time of vasopressin initiation, duration of therapy, tapering discontinuation, and other aspects of therapy.

The purpose of this study was to review current practice at the study institution, to identify variability in the use and administration of vasopressin for septic shock in the medical-surgical ICU setting, and to evaluate the effects on patient safety, with a view to determining whether any intervention is required. The primary objective was to describe the use of vasopressin as an adjunctive vasopressor in adult patients with septic shock who were admitted to the medical-surgical ICU. The secondary objective was to describe the incidence of hypotensive events after discontinuation of vasopressin.

\section{METHODS}

This research study was approved by the local research and ethics board. The institutional review body waived the need for informed consent, given the quality improvement nature of the study.

Patients were identified on the basis of International Classification of Diseases, 9th Revision codes for septic shock. Patient records were reviewed sequentially in reverse chronological order, starting with December 2017, until a total of 100 patients meeting the inclusion criteria were identified. Adult patients who were admitted to the ICU and who were receiving vasopressin and norepinephrine for septic shock were included.

Septic shock was defined according to the 2017 SSC guidelines. ${ }^{6}$ The SSC guidelines did not include the clinical criteria of the Third International Consensus Definitions for Sepsis and Septic Shock, known as Sepsis-3 (i.e., quick Sepsis-Related Organ Failure Assessment [qSOFA]), ${ }^{1}$ because those criteria were not used in the studies that informed the recommendations in the 2017 revision of the SSC guidelines. In accordance with the SSC guidelines, septic shock was based on the presence of 2 or more of the following diagnostic criteria: systemic inflammatory response syndrome (temperature $>38^{\circ} \mathrm{C}$ or $<36{ }^{\circ} \mathrm{C}$, heart rate $>90$ beats $/ \mathrm{min}$, respiratory rate $>20$ breaths $/ \mathrm{min}$ ), proven or suspected infection, new dysfunction of a least one organ, hypotensive events despite adequate fluid resuscitation (where hypotension was defined as systolic blood pressure $<80 \mathrm{~mm} \mathrm{Hg}$, diastolic blood pressure $<50 \mathrm{~mm} \mathrm{Hg}$, and mean arterial pressure $<60 \mathrm{~mm} \mathrm{Hg}$ ), and/or IV norepinephrine requirement of at least $5 \mu \mathrm{g} / \mathrm{min}$ for $6 \mathrm{~h} .{ }^{6}$ Patients receiving vasopressin for brain death, hepatorenal syndrome, or acute cardiac resuscitation were excluded.

Data were collected and recorded by 2 investigators (A.P., A.B.), using a standardized data collection form. Ten percent of the charts from which data were collected were checked by co-investigators to ensure no inter-rater variability. The following information was collected: patient demographic characteristics, admission diagnosis, recent surgical history, Acute Physiology and Chronic Health Evaluation (APACHE) II score, pre-existing comorbidities, source of infection, pathogen type as confirmed by culture, hemodynamic variables at initiation of vasopressin therapy, initial fluid resuscitation volume received, dosage and duration of norepinephrine therapy, dosage and duration of vasopressin therapy, concomitant use of other vasopressors and/or inotropes, 28-day mortality, duration of mechanical ventilation, length of hospital admission, number of days in the ICU, onset of new organ failure during vasopressin therapy, use of renal replacement therapy, and concomitant use of corticosteroids. Occurrences of hypotension, defined as systolic blood pressure less than $80 \mathrm{~mm} \mathrm{Hg}$, diastolic blood pressure less than $50 \mathrm{~mm}$ $\mathrm{Hg}$, mean arterial pressure less than $60 \mathrm{~mm} \mathrm{Hg}$, requirement for re-initiation of vasopressin, or requirement for increased dose of norepinephrine, were collected for up to $4 \mathrm{~h}$ after cessation of vasopressin.

Descriptive statistics were used to analyze the collected data. The findings are reported using quantitative analyses, such as mean with standard deviation or median with interquartile range for continuous variables and percentages for categorical variables.

\section{RESULTS}

A total of 100 patients admitted to the ICU between April and December 2017 were included in the analysis. The baseline characteristics of these patients, along with data concerning the numbers of patients requiring renal replacement therapy and/or mechanical ventilation, the ICU length of stay, and all-cause 28-day mortality, are presented in Table 1 . The mean time to vasopressin initiation was 12.0 (SD 21.6) $\mathrm{h}$ after norepinephrine initiation (Table 2). The mean dose of norepinephrine at the time of vasopressin initiation was 29.5 (SD 19.7) $\mu \mathrm{g} / \mathrm{min}$. The mean vasopressin dose prescribed was 0.04 (SD 0.03) units/min, with a range of tapering and discontinuation regimens observed. The mean duration of vasopressin therapy was 49.1 (SD 65.2) h. Among the 49 patients in whom vasopressin was discontinued 
Table 1. Demographic and Baseline Characteristics

\begin{tabular}{lc} 
Characteristic & $\begin{array}{c}\text { No. of Patients* } \\
(\boldsymbol{n}=\mathbf{1 0 0})\end{array}$ \\
\hline Sex, male & 65 \\
\hline Age (years) (median and IQR) & $65(52-75)$ \\
\hline Weight (kg) (median and IQR) & $84(70-103)$ \\
\hline APACHE II score (median and IQR) & $27(22-31)$ \\
\hline Hemodynamic variables (mean \pm SD)† & \\
Systolic blood pressure (mm Hg) & $83.7 \pm 16.4$ \\
Mean arterial pressure (mm Hg) & $58.2 \pm 11.2$ \\
Heart rate (beats/min) & $98.2 \pm 27.3$ \\
Lactate (mmol/L) & $5.0 \pm 4.6$ \\
White blood cells (x 109/L) & $18.2 \pm 13.3$ \\
\hline Pre-existing conditions and medications & \\
Immunosuppression $\neq$ & 47 \\
Ischemic heart disease & 32 \\
Diabetes & 33 \\
Chronic renal failure & 27 \\
Antiarrhythmic drugs $\S$ & 17 \\
Chronic obstructive pulmonary disease & 17 \\
Alcohol misuse disorder & 14 \\
Congestive heart failure & 10 \\
Cirrhosis & 9 \\
\hline Recent surgical history & 31
\end{tabular}

Admission diagnosis

Sepsis or infection 60

Post-cardiac arrest 9

Acute renal failure $\quad 8$

Pancreatitis 6

Gastrointestinal bleeding 4

Other** 13

Source of infection
Lung

Abdomen 3

Genitourinary $\quad 18$

Skin and soft tissue $\quad 16$

Blood $\quad 30$

Unknown 3

\begin{tabular}{lc}
\hline Pathogen type in culture & \\
Gram-positive & 63 \\
Gram-negative & 60 \\
Fungalt† & 9 \\
\hline
\end{tabular}

Mechanical ventilation (days) $4.6(2.2-7.9)$

(median and IQR)

Renal replacement therapy during vasopressin

Continuous renal replacement therapy 34

Intermittent hemodialysis 3

Hospital length of stay (days) (mean \pm SD) $\quad 26.9 \pm 26.9$

ICU length of stay (days) (mean \pm SD) $\quad 9.8 \pm 9.9$

All-cause 28-day mortality 55

APACHE II = Acute Physiology and Chronic Health Evaluation II,

$\mathrm{IQR}=$ interquartile range, $\mathrm{SD}=$ standard deviation.

*Except where indicated otherwise.

tRecorded from time of initiation of the first vasopressor infusion.

\#Defined as receipt of immunosuppressive medications or absolute

neutrophil count between 500 and $1000 \times 10^{9} / \mathrm{L}$.

§Including sodium-channel blockers and potassium-channel blockers.

TAny of the following types of sepsis or infection: pneumonia, urosepsis, postoperative sepsis, cellulitis, intra-abdominal infection, necrotizing fasciitis, endocarditis, febrile neutropenia, bacteremia, axillar abscess, sepsis of unknown etiology.

**Includes metabolic acidosis, metformin overdose, ruptured esophagus, congestive heart failure, hemoptysis, parastomal hernia, Stevens-Johnson syndrome.

†+Fungal pathogens found by sputum or urine culture were excluded because of their nonpathogenic nature.
Table 2. Characteristics of Medication Therapy

\begin{tabular}{|c|c|}
\hline Characteristic & $\begin{array}{l}\text { Mean } \pm S D * \\
(n=100)\end{array}$ \\
\hline \multicolumn{2}{|l|}{ Norepinephrine } \\
\hline Dose at vasopressin initiation ( $\mu \mathrm{g} / \mathrm{min})$ & $29.5 \pm 19.7$ \\
\hline Dose during vasopressin infusion ( $\mu \mathrm{g} / \mathrm{min})$ & $21.4 \pm 17.2$ \\
\hline $\begin{array}{l}\text { Change in dose } 4 \mathrm{~h} \text { after vasopressin } \\
\text { initiation }(\mu \mathrm{g} / \mathrm{min})\end{array}$ & $-2.8 \pm 14.4$ \\
\hline $\begin{array}{l}\text { Change in dose } 4 \mathrm{~h} \text { after vasopressin } \\
\text { discontinuation }(\mu \mathrm{g} / \mathrm{min})\end{array}$ & $+0.2 \pm 3.1$ \\
\hline Total duration (h) & $78.9 \pm 81.3$ \\
\hline \multicolumn{2}{|l|}{ Vasopressin } \\
\hline $\begin{array}{l}\text { Time of initiation, relative to initiation } \\
\text { of norepinephrine therapy }(h)\end{array}$ & $+12.0 \pm 21.6$ \\
\hline Initial dose (units/min) & $0.04 \pm 0.03$ \\
\hline Mean dose (units/min) & $0.037 \pm 0.005$ \\
\hline Discontinuation dose (units/min) & $0.01 \pm 0.01$ \\
\hline Total duration (h) & $49.1 \pm 65.2$ \\
\hline $\begin{array}{l}\text { Discontinued before norepinephrinet } \\
\text { (no. of patients) }\end{array}$ & 49 \\
\hline \multicolumn{2}{|l|}{ Corticosteroid $\ddagger$} \\
\hline $\begin{array}{l}\text { Received corticosteroid therapy during } \\
\text { vasopressin therapy (no. of patients) }\end{array}$ & 35 \\
\hline Hydrocortisone dose equivalent (mg/day) & $343.5 \pm 289.7$ \\
\hline Total duration (days) & $2.3 \pm 2.0$ \\
\hline \multicolumn{2}{|l|}{$\begin{array}{l}\text { Other inotropes and vasopressors§ } \\
\text { (no. of patients, } n=51 \text { ) }\end{array}$} \\
\hline Epinephrine & 28 \\
\hline Dobutamine & 21 \\
\hline Phenylephrine & 9 \\
\hline Milrinone & 3 \\
\hline \multicolumn{2}{|c|}{$\begin{array}{l}\text { *Except where indicated otherwise. } \\
\text { tFor a total of } 33 \text { patients, norepinephrine and vasopressin were } \\
\text { discontinued at the same time. For } 19 \text { of these patients, } \\
\text { discontinuation was due to withdrawal of care. } \\
\text { Flncludes any IV corticosteroid therapy, with all doses converted to } \\
\text { hydrocortisone equivalents. } \\
\text { §Refers to use of these drugs at any point during the duration of } \\
\text { vasopressin therapy. }\end{array}$} \\
\hline
\end{tabular}

before norepinephrine, the mean dose of norepinephrine at the time of vasopressin discontinuation was 7.8 (SD 6.8) $\mu \mathrm{g} / \mathrm{min}$.

There was an overall decrease $(-2.8[\mathrm{SD} 14.4] \mu \mathrm{g} / \mathrm{min})$ in mean norepinephrine dose once vasopressin was initiated. Approximately one-third of the patients $(n=36)$ experienced no change in norepinephrine requirement to maintain target mean arterial pressure once the vasopressin was discontinued, whereas 18 patients experienced an increase in norepinephrine requirement $(+4.3[S D 2.9] \mu \mathrm{g} / \mathrm{min})$, and 13 experienced a decrease $(-4.5$ [SD 4.3] $\mu \mathrm{g} / \mathrm{min})$. A total of 14 patients had simultaneous discontinuation of norepinephrine and vasopressin, which suggests resolution of shock; another 19 patients had withdrawal of care. The mean total cost of vasopressin therapy per patient was $\$ 77.80$ over a mean duration of $49.1 \mathrm{~h}$. Additional data regarding the regimen of concurrent vasopressin and norepinephrine therapy are presented in Table 2 .

In this study, a total of 60 hypotensive events occurred after discontinuation of vasopressor therapy. Forty-one of these hypotensive episodes occurred among the 49 patients with discontinuation of vasopressin before norepinephrine, whereas 
9 episodes occurred among the 18 patients with discontinuation of norepinephrine before vasopressin. The remaining 10 hypotensive events occurred in the group of 14 patients with discontinuation of both agents at the same time. For 19 patients, no hypotensive events were captured because vasopressors were discontinued as a result of withdrawal of care. Other than these hypotensive events, the only major adverse effect observed was digital ischemia, experienced by 3 patients.

Approximately one-third of the patients $(n=35)$ received systemic corticosteroid therapy during vasopressin infusion, and half $(n=51)$ received other vasopressors and/or inotropes in addition to vasopressin and norepinephrine, which suggests severe refractory or multifactorial shock. A total of 24 (69\%) of the 35 patients who received some form of IV corticosteroid died before the 28-day mortality marker. Details about corticosteroid and additional vasopressor/inotrope therapy are presented in Table 2.

Thirty-seven patients required renal replacement therapy while receiving vasopressin (Table 1), none of whom had previously been receiving long-term renal replacement therapy before admission. Data concerning new-onset organ dysfunction during vasopressin therapy appear in Table 3.

\section{DISCUSSION}

At the study institution, practices for the concomitant use of norepinephrine and vasopressin for septic shock aligned with current guidelines, and vasopressor therapy was initiated after appropriate fluid resuscitation for refractory shock. ${ }^{6}$ Because the VASST trial showed no difference in 28-day mortality between concurrent vasopressin and norepinephrine therapy and norepinephrine alone, ${ }^{4}$ it has been suggested that doses of vasopressin greater than 0.03 units/min may be required in severe septic shock. A small case-control study suggested significant improvement in mean arterial pressure when vasopressin was administered at 0.04 units/min; however, supporting evidence on clinical outcomes such as mortality remains unclear. ${ }^{9}$ Of note, the mean dose documented in the current study was lower than the dose of 0.06 units/min studied in the VANISH trial (Effect of Early Vasopressin vs Norepinephrine on Kidney Failure in Patients with Septic Shock), which showed no improvement in renal failure-free days but increased rates of ischemic events. ${ }^{8}$ In most cases in the current study, vasopressin was initiated at a dose of 0.04 units $/ \mathrm{min}$, and the dose remained stable for the duration of therapy; however, once discontinuation was ordered by the physician, the vasopressin tapering regimens implemented by nursing staff were variable.

As expected, vasopressin initiation facilitated an overall decrease in the hourly rate of norepinephrine infusion to maintain target mean arterial pressure. Although a subgroup analysis in the VASST trial suggested a mortality benefit of vasopressin in patients deemed to have less severe shock, ${ }^{4}$ this description applied to only a minority of our patient population. Although mean
Table 3. Clinically Significant Organ Dysfunction While on Vasopressor Therapy

\begin{tabular}{lc} 
New Organ Dysfunction & $\begin{array}{c}\text { No. of Patients } \\
(\boldsymbol{n}=100)\end{array}$ \\
\hline Renal dysfunction* & 42 \\
Hepatic dysfunctiont & 69 \\
Respiratory failure & 94 \\
\hline *Defined as any of the following: serum creatinine $(\mathrm{SCr}) 3$ times \\
patient's baseline level, increase in $\mathrm{SCr}$ to $\geq 4 \mathrm{mg} / \mathrm{dL}(\geq 353.6 \mathrm{\mu mol} / \mathrm{L})$, \\
initiation of renal replacement therapy, urine output $<0.3 \mathrm{~mL} / \mathrm{kg} / \mathrm{h}$ \\
for $\geq 24 \mathrm{~h}$, or anuria for $\geq 12 \mathrm{~h}$. \\
†Defined as any of the following: international normalized ratio $\geq 1.5$ \\
(not receiving anticoagulation), increased alanine aminotransferase or \\
aspartate aminostransferase $(>3$ times upper limit of normal), bilirubin \\
greater than 3 times upper limit of normal, thrombocytopenia (platelet \\
count $\left.<150 \times 10^{9} / \mathrm{L}\right)$. \\
fDefined as mechanical ventilation and ratio of partial pressure \\
of arterial oxygen to fraction of inspired oxygen $<300 \mathrm{~mm} \mathrm{Hg}$.
\end{tabular}

APACHE II scores in the current study were comparable to those in the VASST trial, approximately $75 \%$ of patients $(n=73)$ required norepinephrine doses of $15 \mu \mathrm{g} / \mathrm{min}$ or more before vasopressin initiation, and nearly one-third of all patients $(n=31)$ were receiving more than $35 \mu \mathrm{g} / \mathrm{min}$, which suggests that our sample included patients who presented with more refractory shock and thus greater risk of death than those in previous trials.

Pneumonia was the most common cause of sepsis, and one-third of patients had microbiologically confirmed bacteremia, which is consistent with the prevalence reported previously ${ }^{2}$; however, the all-cause 28 -day mortality rate (55\%) was higher than expected, which supports the suggestion of higher severity of illness. ${ }^{4,8}$ Given the nature of this study, no conclusions can be drawn about the effect of vasopressin on mortality. Our findings suggest that vasopressin is used as a catecholamine-sparing agent in patients requiring high levels of norepinephrine support to maintain hemodynamics in the treatment of septic shock.

Vasopressin was more commonly discontinued before norepinephrine in this study, which previous research has suggested may increase the likelihood of clinically significant hypotension, ${ }^{10}$ because of the body's inability to regain endogenous function of vasopressin after cessation of exogenous vasopressin. Although hypotension after vasopressor cessation occurred more frequently in patients whose vasopressin was discontinued before norepinephrine, it was largely transient in nature and often required no additional vasopressor support. Half of the patients exhibited no change in norepinephrine requirements $4 \mathrm{~h}$ after vasopressin was stopped, which suggests clinical improvement and possible resolution of the shock state. Given the elimination half-life of vasopressin, any changes in vasopressor requirements beyond this time frame would likely be attributed to a change in the patient's clinical status rather than to discontinuation of vasopressin. In light of the retrospective nature of the study and variable nursing practices for tapering vasopressin, we are unable to draw conclusions about the optimal approach to vasopressin discontinuation in relation to clinical outcomes. 
Dobutamine and epinephrine were most common among the other vasopressors and inotropes used for the patients in this study. Of the patients who received epinephrine, fewer than half survived to the 28-day mortality marker, which suggests that this vasopressor may be added for patients with more severe refractory shock. The prevalence of use of dobutamine and epinephrine suggests that a number of patients exhibited elements of cardiogenic shock. Similar to the use of epinephrine, administration of IV corticosteroids was also associated with higher mortality.

Identification of adverse events was limited to those documented in the interdisciplinary progress notes. Because of the retrospective nature of the study, adverse reactions could not be reliably attributed to specific drug therapy, and causality due to medications could not be established. The SSC guidelines note that vasopressin infusion at a rate higher than 0.03 units/min may be associated with increased risk of cardiac, digital, and splanchnic ischemia, and clinical judgment should be used to determine situations in which a higher dose would be warranted. ${ }^{6}$ The occurrence of 3 documented cases of digital ischemia in this study aligns with the incidence reported in the VASST trial, ${ }^{4}$ although mean doses of vasopressin were higher in our study population. This suggests that a vasopressin dose of 0.04 units/min may be safe and effective, although our study was not specifically designed to investigate safety and effectiveness. Notably, the VANISH trial used a vasopressin dose of 0.06 units $/ \mathrm{min}$ and reported a higher incidence of digital ischemia with no mortality benefit, which suggests that the potential risk may outweigh improvement in clinical outcomes, and should serve as a caution to clinicians considering a higher dose of vasopressin. ${ }^{8}$ In the current study, the 3 patients with digital ischemia required mean doses of norepinephrine greater than $20 \mu \mathrm{g} / \mathrm{min}$ and had prolonged vasopressor infusions (greater than $72 \mathrm{~h}$ ). Fortunately, there were no extravasation events in our study.

This study had several limitations. Although efforts were made to identify and discuss possible sources of confounding, such as the effects of multifactorial pathophysiological shock states (e.g., cardiogenic shock, hypovolemic shock), shifts in patient care goals, and differences in prescribing practices among clinicians, the interpretation of results is limited by the retrospective methodology. Lack of a control group limits our ability to assess causality and associations between findings, which would be hypothesisgenerating for future research. The nature of the clinical environment may have led to incomplete documentation secondary to the complexity of data flowsheets, inconsistency in where information was recorded, or limited time for documentation because of high care demands of the critically ill population. Variability in documentation practices was observed both within and between clinician groups, potentially compromising the accuracy of our results. Finally, clinical decisions, such as initiation of renal replacement therapy or mechanical ventilation, were based on clinician expertise and patient-specific factors, and the observational nature of the data precludes any inference of correlations among medication therapy, disease progression, and adverse effects.

\section{CONCLUSION}

Vasopressin therapy in this study was largely comparable to its use in larger randomized controlled trials and the recommendations in guidelines ${ }^{4,6,8}$; however, variations in time to initiation, titration to discontinuation, and sequence of vasopressor discontinuation were evident. The variability in administration and discontinuation of vasopressin at our centre mimics the variability in the currently available literature guiding vasopressin use. The results of this study have been shared with clinicians and administrators in the study centre to allow further evaluation of routine practices. Although this study showed an effect of vasopressin in promoting hemodynamic stability and lowering norepinephrine requirements, the correlation of vasopressin therapy with improvement in clinical outcomes, such as mortality, remains unclear. Further studies are needed to determine the ideal approach to vasopressin use to ensure consistent clinical practices and optimal patient-centred outcomes. The main adverse events captured by our study were digital ischemia and postdiscontinuation hypotension. Given the retrospective nature of the study, it was not possible to attribute other adverse reactions, such as cardiac ischemia and arrhythmia, to specific drug therapy.

\section{References}

1. Singer M, Deutschman SC, Seymour WC, Shankar-Hari M, Annan D, Bauer M, et al. The third international consensus definitions for sepsis and septic shock (sepsis-3). JAMA. 2016;315(8):801-10.

2. Angus CD, Poll VT. Severe sepsis and septic shock. N Engl J Med. 2013; 369(9):840-51.

3. Hollenberg SM. Vasoactive drugs in circulatory shock. Am J Respir Crit Care Med. 2011;183(7):847-55.

4. Russel JA, Walley KR, Singer J, Gordon AC, Hebert PC, Cooper DJ, et al. Vasopressin versus norepinephrine infusion in patients with septic shock (VASST Trial). N Engl J Med. 2008;358(9):877-87.

5. Multu GM, Factor P. Role of vasopressin in the management of septic shock. Intensive Care Med. 2004;30(7):1276-91.

6. Rhodes A, Evans LE, Alhazzani W, Levy MM, Antonelli M, Ferrer R, et al. Surviving Sepsis Campaign: international guidelines for management of sepsis and septic shock: 2016. Intensive Care Med. 2017;43(3):304-77.

7. Belletti A, Musu M, Silvetti S, Saleh O, Pasin L, Monaco F, et al. Nonadrenergic vasopressors in patients with or at risk for vasodilatory shock. A systematic review and meta-analysis of randomized trials. PLoS One. 2015;10(11):e0142605.

8. Gordon AC, Mason AJ, Thirunayukkarasu N, Perkins GD, Cecconi M, Cepkova $M$, et al. Effect of early vasopressin vs norepinephrine on kidney failure in patients with septic shock: the VANISH randomized clinical trial. JAMA. 2016;316(5):509-18.

9. Tsuneyoshi I, Yamada H, Kakihana Y, Nakamura M, Nakano Y, Boyle WA. Hemodynamic and metabolic effects of low-dose vasopressin infusions in vasodilatory septic shock. Crit Care Med. 2001;29(3):487-93.

10. Hammond DA, McCain K, Painter JT, Clem OA, Cullen J, Brotherton AL, et al. Discontinuation of vasopressin before norepinephrine in the recovery phase of septic shock. J Intensive Care Med. 2019;34(10):805-10.

11. Russel JA. Bench-to-bedside review: vasopressin in the management of septic shock. Crit Care. 2011;15(4):226.

12. Sharshar T, Blanchard A, Paillard M, Raphael JC, Gajdos P, Annane D. Circulating vasopressin levels in septic shock. Crit Care Med. 2003;31(6): 1752-8. 
13. Serpa SN, Nassar AP, Cardoso SO, Manetta JA, Pereira VG, Esposito DC, et al. Vasopressin and terlipressin in adult vasodilatory shock: a systematic review and meta-analysis of nine randomized controlled trials. Crit Care. 2012;16(4):R154.

14. Bissell BD, Magee C, Moran P, Bastin MLT, Flynn J, Flannery AH. Hemodynamic instability secondary to vasopressin withdrawal in septic shock. Am J Respir Crit Care Med. 2017;195:A5767.

15. Lauzier F, Levy B, Lamarre P, Lesur O. Vasopressin or norepinephrine in early hyperdynamic septic shock: a randomized clinical trial. Intensive Care Med. 2006;32(11):1782-9.

16. Gordon AC, Russell JA, Walley KR, Singer J, Ayers D, Storms MM, et al. The effects of vasopressin on acute kidney injury in septic shock. Intensive Care Med. 2010;36(1):83-91.

17. Russell JA, Walley KR, Gordon AC, Cooper DJ, Hebert PC, Singer J, et al. Interaction of vasopressin infusion, corticosteroid treatment, and mortality of septic shock. Crit Care Med. 2009;37(3):811-8.

18. Gordon AC, Mason AJ, Perkins GD, Stotz M, Terblanche M, Ashby D, et al. The interaction of vasopressin and corticosteroids in septic shock: a pilot randomized controlled trial. Crit Care Med. 2014;42(6):1325-33.

Arpita Patel, BSc(Hons), PharmD, was, at the time of this study, an Entry-to-Practice PharmD candidate with the University of British Columbia, Vancouver, British Columbia.
Arielle Beauchesne, PharmD, is with the Lower Mainland Pharmacy Services Residency Program, Vancouver, British Columbia. She is a Post-Graduate Year 1 candidate in the Accredited Canadian Pharmacy Residency program.

Nina Bredenkamp, BSC(Pharm), ACPR, is with the Department of Pharmacy Services, Surrey Memorial Hospital, Surrey, British Columbia.

Rumi McGloin, BSc(Pharm), ACPR, PharmD, is with the Department of Pharmacy Services and the Department of Critical Care, Surrey Memorial Hospital, Surrey, British Columbia.

Sarah N Stabler, BSC(Pharm), ACPR, PharmD, is with the Department of Pharmacy Services and the Department of Critical Care, Surrey Memorial Hospital, Surrey, British Columbia.

Krystin Boyce, BSC, BSC(Pharm), ACPR, is with the Department of Pharmacy Services and the Department of Emergency Medicine, Surrey Memorial Hospital, Surrey, British Columbia.

Competing interests: None declared.

Address correspondence to:

Krystin Boyce

Department of Pharmacy Services and Department

of Emergency Medicine

Surrey Memorial Hospital

13750 96th Avenue

Surrey BC V3V $1 Z 2$

e-mail: krystin.boyce@fraserhealth.ca

Funding: None received.

\section{ON THE FRONT COVER}

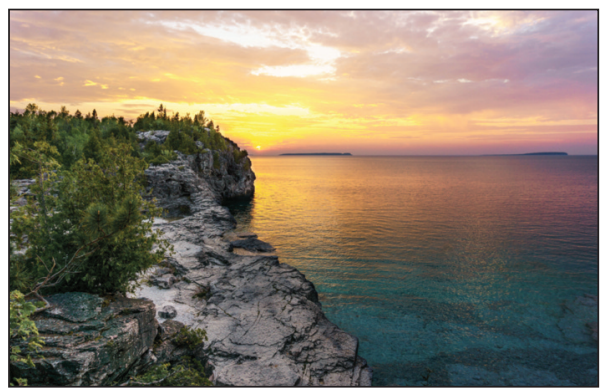

\section{The Grotto, Bruce Peninsula National Park Tobermory, Ontario}

Morgan Patrick took this photograph of The Grotto in Bruce Peninsula National Park using a Sony Alpha a6000 camera. The image was captured during a backcountry hiking trip along the Bruce Peninsula. Morgan is a fourth-year student in the Faculty of Pharmacy and Pharmaceutical Sciences at the University of Alberta.

The CJHP would be pleased to consider photographs featuring Canadian scenery taken by CSHP members for use on the front cover of the Journal. If you would like to submit a photograph, please send an electronic copy (minimum resolution $300 \mathrm{dpi}$ ) to publications@cshp.ca. 